\title{
Differences in Self-evaluation of Narcissism and Therapeutic Relation of Students and Psychotherapists from Different Psychotherapy Schools
}

\author{
Jelena Tovarovic ${ }^{1, *}$, Zorica Knezevic $^{2}$ \\ ${ }^{1}$ Department of Psychology, Faculty of Philosophy, University of Belgrade, Serbia \\ ${ }^{2}$ Department of Psychotherapy, Faculty of Legal and Business Studies, 'Dr Lazar Vrkatić' in Novi Sad, Serbia
}

Copyright $(\mathcal{C} 2015$ by authors, all rights reserved. Authors agree that this article remains permanently open access under the terms of the Creative Commons Attribution License 4.0 International License

\begin{abstract}
Personal characteristics such as narcissism, may affect the therapeutic relationship and the quality of work with clients. The aim of research is to establish whether there are differences in self-evaluation of narcissism and therapeutic relationship between students and psychotherapists of various psychotherapy schools. Research was conducted on the sample of 99 subjects, of whom 38 are psychotherapists from Transactional Analysis, 36 are therapists from Gestalt and 25 are students from Integrative psychotherapy school. The instrument used for evaluation of narcissism is NPI-40 at five-point scale $(\alpha=.91)$, which contains the following dimensions: Authority, Self-sufficiency, Superiority, Exhibitionism, Exploitative, Vanity, and Entitlement. Therapist's relation towards the clients is evaluated by HAQ-II questionnaire $(\alpha=.80)$, which measures positive and negative therapist's relation towards the client. Results show that there are statistically significant differences in total narcissism Also, there are significant differences at various subscales of measured narcissism: Self-sufficiency, Exhibitionism, Exploitative and Entitlement. Results show that there are also differences in negative relation towards the clients, and this is between Gestalt and Integrative. Obtained results may be primarily interpreted by various education profiles and courses of students, future therapists.
\end{abstract}

Keywords Narcissism, Therapeutic Relationship, Transactional Analysis, Gestalt, Integrative

\section{Introduction}

Personality of the psychotherapists, the structure of his character, his experience, his skills and talents are crucial to the start, course and outcome of the psychotherapy (Jerotic, 1989, pp. 49). When various researches started in psychotherapy, the characteristics of the therapists are considered very important for understanding psychotherapeutic outcomes. However, as some authors point out (Garfield, 1997; Beutler, 1997; Strupp \& Anderson, 1997) for more than two decades, emphasizing the specific therapeutic techniques and their effects on certain clinical problems, has led to neglect the importance of studying the characteristics of the therapists. The authors of the study (Ronnestad \& Skovholt, 2003) were investigating the development path of therapists and they have concluded that vulnerability of psychotherapy trainees, particularly in the initial phase of training, can be compared to the vulnerability of clients who are particularly sensitive to how they are perceived by their therapists. Psychotherapeutic modalities differ in the content of education, as well as in terms of selection of candidates and the structure of education, bearing in mind the importance they attribute to the therapists' personality, and by that they can be divided into two groups: the modalities which are based on psychodynamic or humanistic-existential-phenomenal theoretical basis (such as Transactional analysis, Gestalt, and others), and other modalities are based on the theories of learning, such as cognitive-behavioral modalities. In this section shortly, we will describe Transactional analysis and Gestalt psychotherapy orientations as well as Integrative, in other words Integrative psychotherapy that students of Master studies are learning in Serbia.

While there were many theories purporting to explain human behavior before Eric Berne, the most frequently cited and known is the work of Sigmund Freud. Freud emerged in the early $20^{\text {th }}$ century with his theories about personality. Freud believed that personality had three components, all of which must work together to produce our complex behaviors. These three components or aspects were the Id, Ego, and the Superego. It was Freud's belief that these three components needed to be well-balanced to produce reasonable mental health and stability in an individual. According to Freud, the Id functions in the irrational and emotional part of the mind, the Ego functions as the rational part of the mind, and the 
Superego can be thought of as the moral part of the mind, a manifestation of societal or parental values. But perhaps Freud's greatest contribution (and the one that influenced Berne) was the fact that the human personality is multi-faceted. Regardless of the classification or name given to a particular area of personality (id, superego, etc.), each individual possesses factions that frequently collide with each other. And it is these collisions and interactions between these personality factions that manifest themselves as an individual's thoughts, feelings, and behaviors. Another scientist whose contributions impacted Dr. Berne in his development of Transactional Analysis is Dr. Wilder Penfield, a neurosurgeon from McGill University in Montreal. Penfield's experiments focused on the application of electrical currents to specific regions of the brain. Penfield discovered that, when applying current to the temporal lobe of live and alert patients, he would stimulate meaningful memories. In addition, not only were vivid pictures of that person's past revealed, but also the feelings and emotions associated with that event were uncovered. These patients would recite these events, even though in many cases they were events that the patients were unable to recollect on their own. Before Berne first published his theories on Transactional Analysis, he spent years formulating the framework of this approach. The key to this methodology was a transaction - the fundamental unit of social intercourse. Berne also defined a stroke - the fundamental unit of social action. With this definition, Dr. Berne defined the basic unit of analysis. At its simplest level, Transactional Analysis is the method for studying interactions between individuals. By identifying and standardizing upon a single unit, development and promotion of this theory was easily facilitated. Psychotherapists were able to read about Berne's theories and test them out in their own practices. It should be noted that this approach was profoundly different than that of Freud. While Freud and most other psychotherapists took the rather simplistic approach of asking the patient about themselves, Berne took an alternate approach to therapy. Berne felt that a therapist could learn what the problem was by simply observing what was communicated (words, body language, facial expressions) in a transaction. So instead of directly asking the patient questions, Berne would frequently observe the patient in a group setting, noting all of the transactions that occurred between the patient and other individuals (Berne, 1964; Stewart, 1992).

The basic philosophy of Gestalt therapy is that a person tends to wholeness and integration of thinking, feeling and behavior. This perspective is opposed to determinism, believing that a person has the ability to notice the way in which his early experiences are associated with the current difficulties. Gestalt therapy is based on the here and now, emphasizes the importance of personal choice and responsibility. In other words, the emphasis is on what and how something is perceived, here and now, in order to assist the client to accept their polarity. The goal of Gestalt therapy is to help clients become more aware of current experience and increase their ability to make the right choices, the goal is not analysis, but integration. Central importance is given to I-You relationship and quality of the therapists' presence. Therapists' attitudes and behavior are more important than the techniques that are being used. The therapist does not interpret the client, but instead helps them to come to their own interpretations. Clients recognize the unfinished business from the past that interfere with the current functioning and work on them (Humphrey, 1924; Barber, 2006).

Psychotherapists who are going to Master studies, they learn different therapeutic directions, in addition to Gestalt and Transactional Analysis they are familiar with the concepts of Systemic family therapy (in which the family is viewed as interactive, in systematic manner and it is a context that helps us understand how people function in relations with others and how to conduct), behavioral and cognitive-behavioral therapy (aimed at behavior as a result of learning in terms of behavior; while the basic assumption of cognitive-behavioral therapy is that people tend to adopt a wrong way of thinking, which leads to the disorder of emotions and behavior, and cognitive processes are the main determinants of our feelings and actions; therapy is primarily focused on cognition and behavior, emphasizes the role of thinking, decision making, questioning, operation and making new decisions).

In what the modalities differ is the focus on certain segments of education. We can distinguish: (a) education aimed at personality trainees/future therapists; and (b) training aimed at mastering the techniques that will be applied by the therapists. The first educational approach is inherent method, which is based on psychodynamic or humanistic-existential-phenomenal theory. During training therapists explore their personal experience, because the assumption of this psychodynamic orientation is that the outcome of the psychotherapeutic process is crucial for quality of the relation between the client and psychotherapist. Other educational approach is inherent to cognitive-behavioral therapies. Segment of the personality trainees is here reduced to a minimum, we could even say that in terms of targeted changes in the future therapists are practically nonexistent. Trainees assume the role of a patient solely for demonstration purposes in the function of training under direct supervision, because the approach believes that it does not matter who is doing, but only what and how the psychotherapy process works, and what techniques are applied.

There has been a realization that psychotherapy is not just what therapists do, but also what the therapist is as a person (Milenkovic, 1997; Goldberg, 2001). In this context, some authors point out that a large number of psychotherapists are emotionally unstable and that is what can influence the clients (Goldberg, 2001). As we have mentioned Transactional analysis and Gestalt therapists are dealing with personalities of the trainees and future therapists within the education process. Students of Master studies are learning Integrative psychotherapy, so that in addition to the work on their own personality, they are also considering different 
techniques from other modalities that they should apply in the therapeutic process.

Therapeutic relationship is very important aspect in psychotherapeutic process. What happens when psychotherapists have higher self-love or narcissism, does that helps or enables them to communicate positively and productively with their clients? Narcissism is recognized as an important complex of personality traits. Narcissism is the dimension of personality which includes, at one end, high self-preoccupation and conceit, putting one's own wishes and needs above the wishes and needs of other people, showing unusual grandiosity, deep sense of having right to something and lack of empathy for other people's feelings, needs and wishes (Larsen \& Buss, 2007). Definition from psychoanalytic glossary describes narcissism as the state of self-love focused on one's own ego, i.e. the image of one's own ego, the state in which erotic libidinous relations with people and with objects were not established or were discontinued (Trebjesanin, 2012). Narcissists are characterized by a highly positive or inflated self-concept. Narcissists use a range of intrapersonal and interpersonal strategies for maintaining positive self-views. For example, narcissists respond to critical feedback with anger and self-enhancing attributions (Campbell, Reeder, Sedikides \& Elliot, 2000), fantasize about fame or power (Raskin \& Novacek, 1991), and derogate those who provide threatening feedback (Kernis \& Sun, 1994).

Since 1977, in many studies a statistical procedure of meta-analysis has been applied. The first meta-analysis had been carried out by Smith and Glass (Glass \& Smith, 1977; Smith, Glass \& Miller, 1980). However, we will present a recent meta-analysis by Beutler and his colleagues (2004). In a recent edition of the Handbook of Psychotherapy and Behavior Change authors have maintained classification variables of the psychotherapists in two mutually independent dimensions:

1. Observable versus concluded variables - under the observable variables they include those variables that can be known independently of the psychotherapist, that are actually observation and the documentation (e.g., gender, age, used interventions); while the variables that are named as concluded, there is no objective record. They are self-evaluation of the psychotherapists (for example, attitudes towards gender, religious beliefs, theoretical orientation).

2. Personality versus states of personality - personality traits are characteristics of the psychotherapists that are independent of the psychotherapeutic process, while the state of personality are specific to the psychotherapeutic situation and are part of the therapeutic process.

In this article we will not deal with the presentation of all results of this study (Beutler et al., 2004), who actually presented the results in the four quadrants according to the previous edition of the Handbook (Bautler, Machado \& Neufeldt, 1994). The four quadrants are $>$ observable personality traits, the observable personality states, concluded personality traits and concluded personality state.
It is noteworthy, that concluded personality traits including personality traits such as: mechanisms to overcome the crisis, psychotherapists well-being, its beliefs, values and cultural attitudes. Also, personality traits of the psychotherapists are often influenced by how he perceives and responds to the client, and it could on the other hand influence the client's responses. In study of Tremblay, Herron and Schultz (1986) they have administered the Personality Orientation Inventory to 90 male and 90 female psychotherapists to investigate the relation between theoretical orientation and personality. Ss were self-designated as an equally distributed among behavioral (BEH), psychodynamic (PSY), and humanistic (HUM) groups. Results suggest the existence of a core therapist personality, with separate personality patterns for each orientation. However, the patterns were more overlapping than they were unique. HUMs had the most unique positive personality traits. They differed from BEHs on flexibility, acceptance of personal aggression, sensitivity to their own feelings, and development of intimate relationships. They differed from both BEHs and PSYs in being more inner-directed, affirming of self-actualizing values, and expressing feelings in action. BEHs were most like PSYs, who, in turn, shared more with HUMs. The unique BEH behavioral constellation was relatively limited flexibility, acceptance of their own feelings, and development of relationships. In other research conducted in Serbia, on a sample of 13 therapists and 282 of their trainees of different modalities, the results indicated that differences in professional and personal ego ideals of psychotherapy trainees/future therapists may be considerably higher between groups of the same psychotherapeutic modality. The author concludes that the formation of the ego-ideal in the future psychotherapists is connected with the personality of their therapists-educators, both in humanistic and cognitive-behavioral orientation (Sakotic-Kurbalija, 2006).

Campbell (1999) suggests that narcissists have interpersonal relationships that lack in commitment and caring. Although it seems that narcissistic person has high self-respect, the person is actually doubtful about him/herself, and therefore constantly needs praise and attention, and we call this phenomenon narcissistic paradox. (Larsen \& Buss, 2007) The person has grandiose feeling of self-importance, but he/she is still "vulnerable to attacks" on his/her self-respect and cannot stand criticism very well.

All forms of psychotherapy, whatever their underlying theories, and no matter what techniques they use, attempt to promote beneficial changes in a patient's attitudes and symptoms through the influence of a therapist with whom the patient has a close relationship (Frank, 1959). There is a relationship between the client and the psychotherapist that is full of understanding, unconditional acceptance and trust, where the client can speak openly about him/herself and about problems. This is the relationship, in which two persons voluntarily meet, with clear rules, aims and limits related to their interaction. Psychotherapist is always aware that his/her relation with the client should urge the client to change, but also it is not up to him/her to tell the client what 
to do. Understanding, acceptance and mutual respect are the most important in the relationship itself. Relationship between the therapist and the client is the basis of psychotherapeutic process. As McConnaughy concludes the nature of the therapist's approach to clients is determined by who the therapist is as a person. The personal development, interpersonal style, and life experiences of the therapist shape the emotional climate, theoretical perspective, and techniques that the therapist offers to clients when they present for treatment. A wealth of clinical and theoretical writings underscore the relevance of the therapist's personal contribution to the quality of the therapy, and the psychotherapy research literature supports and strengthens this position. McConnaughy surveys some of the research literature in his paper and a truism which is noted that therapists should be well developed and comfortable with themselves and able to relate effectively with others. The concomitant is that practitioners who are insufficiently mature will have much difficulty in attending to clients' needs. The dynamics of the therapy relationship lies in the space in between each practitioner and client.

However, many therapeutic schools have different approaches to the therapeutic relationship. Personal characteristics such as narcissism, may affect the therapeutic relationship and therefore the quality of work with clients. The key assumption of research is that self-evaluation of narcissism degree and therapeutic relationship differs in students and psychotherapists from various psychotherapy courses. As far as the course in psychotherapy is concerned, we refer to students at university level (master in psychotherapy, integrative psychotherapy school) and trainees of various private Training psychotherapy schools (Transactional analysis and Gestalt therapy). As previously mentioned psychodynamic approaches are oriented more to the personality of the therapist, while students that are learning Integrative psychotherapy, in addition to direction on the personality of the therapists they are also oriented towards the use of various techniques that are integrated in Cognitive-behavioral modalities and Systemic family therapy. Therefore, the Transaction analysis and Gestalt psychotherapists should not differ in terms of personality traits in relation to students of Integrative orientation. This further implies that Transactional analysis and Gestalt therapists are more directed at themselves, improve and change their personality traits when required. However, students of Integrative psychotherapy have a special course on the therapeutic relationship. Accordingly, it is assumed that the modalities differ in personality traits, as well as the therapeutic relationship. Therefore, the aim of research is to establish whether there are differences in self-evaluation of narcissism and therapeutic relationship between students and psychotherapists of various courses and psychotherapy schools. Special hypothesis of research is that students and practical therapists, from Gestalt and Transactional analysis, have lower scores in narcissism as compared with psychotherapists from Integrative who pursue academic education. Also, there is another hypothesis that therapists from Integrative will achieve higher scores in positive therapeutic relationship, considering the fact that they study therapeutic relationship as a subject during their studies.

\section{Methodology}

Procedure: The research was conducted in January of 2015. The participants answered on questionnaires during the psychotherapist group meetings or via mail. The testing of participants was anonymous and there were no any issues during the time when research was conducted.

Sample: Research was carried out on the sample of 99 participants. There were 38 psychotherapists from Transactional Analysis, 36 are therapists from Gestalt and 25 are therapists from Integrative psychotherapy school in Serbia. Respondents who are the youngest are 20 years old, while the oldest are 55 years old, and the average age is 31 . There are 88 female therapists and students $(88.9 \%)$ and 11 male therapists and students (11.1\%). As mentioned, we refer to students at university level (master in psychotherapy, integrative psychotherapy school) and trainees of various private Training psychotherapy schools (Transactional analysis and Gestalt therapy).

Measures: The instrument used for evaluation of narcissism is NPI-40, five-point scale $(\alpha=.91)$, which contains the following dimensions: Authority, Self-sufficiency, Superiority, Exhibitionism, Exploitative, Vanity, and Entitlement. Therapist's relationship towards the clients is evaluated by HAQ-II questionnaire $(\alpha=.80)$, which has 19 items and measures Positive and Negative therapist's relationship towards the client.

\section{Results and Discussion}

We have presented results in narcissism, its subscales and therapeutic relationship between Transactional analysis, Gestalt and Integrative psychotherapeutic schools, using ANOVA statistical method. In Table 1. descriptive statistics are showed for narcissism, its subscales and positive and negative relationship towards clients. Results indicate that there are statistically significant differences in: Total narcissism $(\mathrm{df}=2, \mathrm{~F}=5.189, \mathrm{p}=0.007)$, and Exhibitionism $(\mathrm{df}=2, \mathrm{~F}=3.870, \mathrm{p}=0.024)$, where Gestalt and Integrative have higher scores than Transactional analysis (TA); Self-sufficiency $(\mathrm{df}=2, \mathrm{~F}=3.375, \mathrm{p}=0.038)$, Exploitative subscale $(\mathrm{df}=2, \mathrm{~F}=5.189, \mathrm{p}=0.007)$, and Entitlement $(\mathrm{df}=2$, $\mathrm{F}=6.254, \mathrm{p}=0.003$ ), where Integrative has higher scores than Gestalt and TA; Negative relationship towards clients $(\mathrm{df}=2$, $\mathrm{F}=3.142, \mathrm{p}=0.048$ ), where $\mathrm{TA}$ and Integrative have lower scores than Gestalt. However, there are no significant differences in following dimensions: Authority $(\mathrm{df}=2$, $\mathrm{F}=2.394, \mathrm{p}=0.097)$, Superiority $(\mathrm{df}=2, \mathrm{~F}=2.252, \mathrm{p}=0.111)$, Vanity $(\mathrm{df}=2, \mathrm{~F}=2.054, \mathrm{p}=0.134)$, Positive relationship towards client $(\mathrm{df}=2, \mathrm{~F}=2.641, \mathrm{p}=0.076)$. 
Table 1. Descriptive statistics of narcissism, its subscales, positive, and negative relationship towards clients of Transactional analysis, Gestalt and Integrative psychotherapeutic school.

\begin{tabular}{|c|c|c|c|c|c|}
\hline & & Mean & Std. Deviation & Minimum & Maximum \\
\hline \multirow[t]{4}{*}{ Authority } & Gestalt & 25.69 & 3.963 & 15 & 33 \\
\hline & TA & 23.45 & 5.708 & 10 & 35 \\
\hline & Integrative & 25.64 & 4.872 & 17 & 33 \\
\hline & Total & 24.82 & 4.991 & 10 & 35 \\
\hline \multirow[t]{4}{*}{ Self-sufficiency } & Gestalt & 18.31 & 3.152 & 9 & 24 \\
\hline & $\mathrm{TA}$ & 18.68 & 3.580 & 9 & 25 \\
\hline & Integrative & 20.44 & 3.001 & 14 & 26 \\
\hline & Total & 18.99 & 3.367 & 9 & 26 \\
\hline \multirow[t]{4}{*}{ Superiority } & Gestalt & 16.19 & 3.504 & 7 & 21 \\
\hline & $\mathrm{TA}$ & 15.21 & 3.155 & 8 & 21 \\
\hline & Integrative & 17.00 & 3.342 & 9 & 22 \\
\hline & Total & 16.02 & 3.375 & 7 & 22 \\
\hline \multirow[t]{4}{*}{ Exhibitionism } & Gestalt & 20.61 & 6.058 & 11 & 29 \\
\hline & $\mathrm{TA}$ & 17.92 & 4.364 & 9 & 28 \\
\hline & Integrative & 20.92 & 3.718 & 13 & 28 \\
\hline & Total & 19.66 & 5.059 & 9 & 29 \\
\hline \multirow[t]{4}{*}{ Exploitative } & Gestalt & 13.53 & 2.420 & 9 & 18 \\
\hline & $\mathrm{TA}$ & 12.74 & 3.916 & 5 & 21 \\
\hline & Integrative & 15.68 & 4.161 & 10 & 23 \\
\hline & Total & 13.77 & 3.672 & 5 & 23 \\
\hline \multirow[t]{4}{*}{ Vanity } & Gestalt & 8.75 & 3.805 & 3 & 14 \\
\hline & $\mathrm{TA}$ & 7.95 & 3.110 & 3 & 14 \\
\hline & Integrative & 9.56 & 1.660 & 6 & 12 \\
\hline & Total & 8.65 & 3.147 & 3 & 14 \\
\hline \multirow[t]{4}{*}{ Entitlement } & Gestalt & 16.97 & 4.681 & 9 & 27 \\
\hline & TA & 16.29 & 4.826 & 7 & 25 \\
\hline & Integrative & 20.20 & 3.379 & 11 & 26 \\
\hline & Total & 17.53 & 4.685 & 7 & 27 \\
\hline \multirow[t]{4}{*}{ Negative relation } & Gestalt & 15.36 & 3.498 & 11 & 23 \\
\hline & $\mathrm{TA}$ & 14.82 & 3.660 & 9 & 23 \\
\hline & Integrative & 13.20 & 2.661 & 7 & 21 \\
\hline & Total & 14.61 & 3.449 & 7 & 23 \\
\hline \multirow[t]{4}{*}{ Positive relation } & Gestalt & 58.50 & 4.820 & 47 & 68 \\
\hline & $\mathrm{TA}$ & 55.95 & 5.136 & 48 & 66 \\
\hline & Integrative & 56.76 & 4.390 & 48 & 63 \\
\hline & Total & 57.08 & 4.923 & 47 & 68 \\
\hline
\end{tabular}

Results indicate that there are differences in total narcissism between Integrative and Gestalt, as well as between Integrative and Transactional analysis. Also, at subscales of Self-sufficiency, Exploitative subscale and Entitlement, there are statistically significant differences between Integrative psychotherapeutic school and Gestalt and Transactional analysis. Descriptive statistics, i.e. mean scores, indicate that subjects from Integrative have higher scores at aforementioned subscales. At Exhibitionism subscale, Transactional analysis differs from Gestalt and Integrative, i.e. they have lower scores. Results at the subscale of Negative therapeutic relationships show that there are differences between subjects from Integrative therapeutic school and Transactional analysis and Gestalt therapists. Also, sample from Integrative have lower scores at this subscale.

These results are consistent with the research conducted on sample of 74 participants of Transactional analysis and Gestalt psychotherapy school students, where authors concluded that there are differences in narcissism and its subscales between these two groups (Tovarovic and Knezevic, 2015). However, not many studies are investigating narcissism or any other important personality trait in psychotherapists that can impact relationship between client and therapist. 
Table 2. Multiple comparisons on narcissism, its subscales, and negative relationship towards clients between Transactional analysis, Gestalt and Integrative psychotherapeutic school.

\begin{tabular}{|c|c|c|c|c|c|}
\hline Dependent Variable & (I) & $(\mathrm{J})$ & (I-J) & Std. Error & Sig. \\
\hline \multirow{2}{*}{ Self-sufficiency } & \multirow{2}{*}{ Int } & Ges & $2.134(*)$ & .856 & .014 \\
\hline & & $\mathrm{TA}$ & $1.756\left(^{*}\right)$ & .847 & .041 \\
\hline \multirow[t]{2}{*}{ Exhibitionism } & \multirow[t]{2}{*}{ TA } & Ges & $-2.690(*)$ & 1.144 & .021 \\
\hline & & Int & $-2.999(*)$ & 1.266 & .020 \\
\hline \multirow[t]{2}{*}{ Exploitative } & \multirow[t]{2}{*}{ Int } & Ges & $2.152(*)$ & .916 & .021 \\
\hline & & TA & $2.943(*)$ & .906 & .002 \\
\hline \multirow[t]{2}{*}{ Entitlement } & \multirow[t]{2}{*}{ Int } & Ges & $3.228(*)$ & 1.159 & .006 \\
\hline & & TA & $3.911\left(^{*}\right)$ & 1.146 & .001 \\
\hline \multirow[t]{2}{*}{ Negative relationship } & \multirow[t]{2}{*}{ Int } & Ges & $-2.161\left(^{*}\right)$ & .879 & .016 \\
\hline & & $\mathrm{TA}$ & -1.616 & .869 & .066 \\
\hline \multirow[t]{2}{*}{ Narcissism total } & \multirow[t]{2}{*}{ Int } & Ges & 9.384 & 5.412 & .086 \\
\hline & & TA & $17.203(*)$ & 5.354 & .002 \\
\hline
\end{tabular}

*(I) - Psychotherapy school; (J) - Psychotherapy school; (I-J) - Mean difference; Int - Integrative; TA - Transactional analysis; Ges - Gestalt.

\section{Conclusions}

The aim of research is to establish whether there are differences in self-evaluation of narcissism and therapeutic relationship between students and psychotherapists of various courses and psychotherapy schools. We have confirmed by this research that there are differences between evaluation of students and therapists in total narcissism and its dimensions, as well as in negative relationship towards the clients. Results show that students from Integrative psychotherapy have the highest scores in narcissism and its dimensions, while the lowest score of students from Integrative is notice at subscale negative relationship towards the clients.

Students from Integrative psychotherapeutic school have higher scores at Self-sufficiency subscale than therapists from Transactional analysis and Gestalt, i.e. they think they have abilities to make decisions and to perform certain task at proper manner; they also have higher scores at Exploitative subscale, in other words, they think that they can persuade other people to think in the same or in the similar way as they do; while higher scores at the subscale of Entitlement of students from Integrative psychotherapy indicate that respect of other people is very important for them, and that they can achieve whatever they want. At Exhibitionism subscale Transactional analysis psychotherapists have lower scores than therapists from Gestalt and subjects from Integrative, which indicates that they are more modest and that they do not want to be in the center of attention.

Students from Integrative psychotherapeutic school have lower scores at the subscale of Negative therapeutic relationship than therapists from Gestalt and Transactional analysis, which indicates that students think that clients trust them, that they productively exchange opinions with clients and that they understand them and their needs and problems.
Lower scores at the subscale of negative relationship and their interpretation confirm that students from Integrative have higher self-confidence and that they trust in their abilities more than therapists from Gestalt and Transactional analysis.

The beginning of professional training can be an exciting, but also very demanding path, because it represents a transition from the known role of lay helpers into the unfamiliar role of professional therapists (Ronnestad \& Skovholt, 2003). Students who are learning certain psychotherapeutic orientation are reviewing what kind of personality traits are needed for this type of work. In this process educators and supervisors should help them to construct and develop as professional therapists. Direct, real or non constructive criticism could have negative effect on their confidence. Therefore, supervisors should give constructive criticism that would help them in further professional development of students and future therapists. Psychotherapists who do not have supervision and are independent, positive contact and relationships with clients plays a key role in the continued therapeutic process. The feedbacks that psychotherapists could get from clients are significant in the development of not only a positive therapeutic relationship, but also in a lifework of therapists as persons. In addition, psychotherapists colleagues can also provide them constructive criticism or advice to contribute to the development of trainees and psychotherapists. Constant education and training such as how to become a better therapist, how to improve communication with clients or how to improve the therapeutic relationship, and many others, can contribute to the professional development of current and future therapists.

We can interpret results by various educational profile and field of expertise of students, future therapists. Students from Integrative psychotherapeutic school have finished master studies of psychology, psychotherapy department, while subjects from Gestalt and Transactional analysis did not have 
the same education profile. Integrative model is based on development-relationship model and it puts emphasis on therapeutic relationship. Implications for further studies may be to conduct study on larger sample of subjects and possibly to include other psychotherapeutic groups as well.

\section{REFERENCES}

[1] Barber, P. (2006). Becoming a practitioner researcher: A Gestalt approach to holistic inquiry. London: Middlesex University Press.

[2] Berne, E. (1964). Games People Play - The Basic Hand Book of Transactional Analysis. New York: Ballantine Books.

[3] Beutler, L. E. (1997). The psychotherapist as a neglected variable in psychotherapy: An illustration by reference to the role of therapist experience and training. Clinical psychology: Science and practice, 4 (1), 44-52.

[4] Beutler, L. E., Machado, P. P. P., \& Neufeldt, S. (1994). Therapist variables. In: S. L. Garfield \& A. E. Bergin (Eds.), Handbook of Psychotherapy and Behavior Change (4th Edition) (pp. 259-269). New York: John Wiley \& Sons.

[5] Beutler, L. E., Malik, M., Shabia, A., Hardwood, T. M., Telebi, H., Noble, S. and Wong, E. (2004). Therapist Variables. In: M. J. Lambert (ed.). Bergin and Garfield's (Eds.), Handbook of Psychotherapy and Behaviour Change (5th Edition) (227-306). New York: John Wiley \& Sons.

[6] Campbell, W. K. (1999). Narcissism and romantic attraction. Journal of Personality and Social Psychology, 77, 1254-1279.

[7] Campbell, W. K., Reeder, G. D., Sedikides, C., \& Elliot, A. T. (2000). Narcissism and comparative self-enhancement strategies. Journal of Research in Personality, 34, 329-347.

[8] Frank, J. D. (1959). The dynamics of the psychotherapeutic relationship: Determinants and effects of the therapist's influence. Psychiatry, 22 (1), 17-39.

[9] Garfield, S. (1997). The therapist as neglected variable in psychotherapy research, Clinical psychology: Science and practice, 4 (1), 40-43.

[10] Goldberg, C. (2001). Influence and moral agency in psychotherapy. International Journal of Psychotherapy, 6 (2), 107-114.

[11] Humphrey, G (1924). The psychology of the gestalt. Journal of Educational Psychology 15 (7), 401-412.

[12] Jerotic, V. (1989). Indications for individual and group psychotherapy. In: Popovic, M. and Jerotic V.
Psychodynamic and psychotherapy of neurosis (pp. 39-55). Belgrade: Zavod za udžbenike i nastavna sredstva.

[13] Kernis, M. H., \& Sun, C. (1994). Narcissism and reactions to interpersonal feedback. Journal of Research in Personality, 28, 413.

[14] Larsen, R. J., \& Buss, D. M. (2007). Psychology of personality. Jastrebarsko: Naklada Slap.

[15] McConnaughy, E.A. (1987) The personality of the therapist in psychotherapeutic practice. Psychotherapy, 24 (3), 303-314.

[16] Milenkovic, S. (1997). Value of contemporary psychotherapy: 1001 psychotherapy stories. Novi Sad: Prometej.

[17] Raskin, R. N., \& Novacek, J. (1991). Narcissism and the use of fantasy. Journal of Clinical Psychology, 47, 490-499.

[18] Ronnestad, M. H. \& Skovholt, T. M. (2003). The Journey of the Counselor and Therapist: Research Findings and Perspectives on Professional Development. Journal of Career Development, 30 (1), 4-44.

[19] Sakotic-Kurbalija, J. (2006). Personality of psychotherapists: self-image and professional ego-ideals of trainers and trainees in different psychotherapeutic orientations (Master thesis). Novi Sad: Faculty of Philosophy.

[20] Smith, M. L., \& Glass, G. V. (1977). Meta-analysis of psychotherapy outcome studies. American Psychologist, 32 (9), 752-760.

[21] Smith, M. L., Glass, G. V., \& Miller, T. I. (1980). The benefits of psychotherapy. Baltimore: Johns Hopkins University Press.

[22] Stewart, I. (1992). Eric Berne: Volume 2 of Key Figures in Counselling and Psychotherapy. London: Sage Publications.

[23] Strupp, H. H., \& Anderson, T. (1997). On the limitation of therapy manuals. Clinical psychology: Science and practice, 4 , 76-82.

[24] Tovarovic, J., \& Knezevic, Z. (2015, March). Differences in narcissism between the beginners level and higher educational level of psychotherapists. In Book of Abstracts: Empirical Researches in Psychology. Paper presented at the Proceedings of the $21^{\text {st }}$ National Conference Empirical Researches in Psychology, Serbia (pp. 132-133). Belgrade: Faculty of Philosophy University of Belgrade.

[25] Trebjesanin, Z. (2012). A Lexicon of psychoanalysis. Belgrade: Zavod za udzbenike.

[26] Tremblay, J. M., Herron, W. G., \& Schultz, C. L. (1986). Relation between therapeutic orientation and personality in psychotherapists. Professional Psychology: Research and Practice, 17 (2), 106. 